\title{
Different Crude Extracts of Cinnamomum tamala with Antioxidant and Antibacterial Capabilities
}

\author{
Surya Kant Kalauni ${ }^{1 *}$, Rasna Maharjan ${ }^{1 *}$, Ishwor Pathak ${ }^{2}$, Karan Khadayat ${ }^{1}$, Muna Niraula ${ }^{1}$ Prakash Thapa ${ }^{1}$ \\ ${ }^{1}$ Central Department of Chemistry, Tribhuvan University, Kathmandu, Nepal \\ ${ }^{2}$ Department of Chemistry, Amrit Campus, Tribhuvan University, Kathmandu, Nepal \\ *E-mail: skkalauni@gmail.com; rasnamaharjan04@gmail.com
}

(Received:3 March 2021, Received in revised form: 18 April, Accepted: 22 June 2021, Available Online)

\section{Highlights}

- Methanolic and ethanolic extracts of young and mature leaves of Cinnamomum tamala were prepared.

- Antioxidant and antibacterial capabilities of the extracts were evaluated.

- The methanolic extract of young leaves is more potent in terms of antioxidant activity.

- All extracts showed potent antibacterial activity against gram-negative strain than gram-positive strain.

\begin{abstract}
In this present study, crude extracts of young and mature leaves of Cinnamomum tamala were evaluated for their antioxidant and antibacterial capabilities. The cold percolation method was carried out with polar solvents methanol and ethanol. The antioxidant activities of all the extracts were assessed by DPPH assay and antibacterial properties were performed against Staphylococcus aureus, Escherichia coli, Salmonella typhi, and Klebsiella pneumoniae by agar well diffusion method. All extracts were able to scavenge free radicals in which strong antioxidant activity was found in methanolic extract of young leaves, and its $I C_{50}$ value was estimated as $(67.19 \pm 14.96 \mu \mathrm{g} / \mathrm{mL})$ at a concentration range of $31.25-500 \mu \mathrm{g} / \mathrm{mL}$ while $I C_{50}$ value of standard ascorbic acid was found to be $33.53 \pm 0.97 \mu \mathrm{g} / \mathrm{mL}$ at the concentration range of $10-50 \mu \mathrm{g} / \mathrm{mL}$. The ethanolic extract of leaves $(Z O I=19 \mathrm{~mm})$ showed strong antibacterial activity while standard neomycin showed $(Z O I=23 \mathrm{~mm})$ against Escherichia coli at a concentration of $50 \mu \mathrm{g} / \mathrm{mL}$. These results may provide scientific evidence of the traditional uses of C. tamala. Isolation and characterization of pure active compounds should be done in the future.
\end{abstract}

Keywords: C. tamala, extracts, phytochemicals, antioxidant, antibacterial

\section{Introduction}

The physiographic and climatic variability have been reflected in a vibrant chemical diversity in Nepal [1]. The chemical variety of plants, animals, insects, and microorganisms has led to spectacular discoveries made over the last 150 years that have been credited to the indigenous peoples, who discovered and shared their knowledge of herbal and animal remedies between the communities and generations. Later, synthetic chemists used their skills to isolate, characterize, and reconstruct the molecular structures leading to the most fascinating bioactive natural products [2], [3]. For centuries, different medicinal plants are being used as a traditional medicine to heal some peculiar diseases in Nepal [4-6]. However, the knowledge of traditional healers will be extinct as peoples get more and more marginalized. Thus, scientifically exploitation of locally available medicinal plants is a blooming requirement for the therapeutic approach and the most effective formulation aspect of drugs with few or hardly adverse effects [7]. Among the various medicinal plants, the present study attempts to highlight C. tamala (Buch.-Ham.) T. Nees and Eberm (Lauraceae). This species is an evergreen tree naturally grown in Nepal between 450-2100 $\mathrm{m}$ in height [8], [9].

${ }^{*}$ Corresponding author 
The leaves of $C$. tamala have been used for flavouring food due to their aroma [9]. Besides these, it is also a traditional dyeyielding plant and natural food preservative for pineapple juice [10], [11]. Dried leaves and bark of $C$. tamala were prescribed for children for fever, anaemia, and body odour. Its seeds were crushed and mixed with honey or sugar for dysentery or cough. Additionally, parts of $C$. tamala have been used in the digestive system (acidity, lack of appetite, abdominal pain), respiratory disease (bronchitis, cold and cough), and circulatory system as reported [12]. Several previous studies reported C. tamala as an antioxidant, antidiabetic, anticancer and antiinflammatory [13-22].

Therefore, in vitro assessment of young and mature leaves of $C$. tamala for their antioxidant and antimicrobial capabilities is the main objective of this research.

\section{Materials and Methods}

\section{Collection and authentication of plant materials}

Fresh young and mature C. tamala leaves were collected separately from Machhegaun, Kathmandu, during July 2019. A herbarium specimen was authenticated with a voucher code (RM001) was deposited at the Central Department of Botany, Tribhuvan University. The collected young and mature leaves were shade dried, ground, and preserved in airtight bottles.

\section{Extraction}

The dried plant samples were extracted thrice with methanol and ethanol by cold percolation method for 72 hours in a conical flask with occasional shaking. The filtered extracts were then evaporated under vacuum at $40{ }^{\circ} \mathrm{C}$ to dryness with the help of a rotary evaporator to obtain crude extract and left for dryness.

\section{Antioxidant activity}

In vitro antioxidant activity of respective crude extracts was evaluated by following the standard protocol [23]. An aliquot $100 \mu \mathrm{L}$ of plant extract $(31.25-500 \mu \mathrm{g} / \mathrm{mL})$ was mixed with $100 \mu \mathrm{L}$ of DPPH $(0.1 \mathrm{mM})$ solution. The reaction mixture was then incubated for $15 \mathrm{~min}$ in the dark at room temperature, and absorbance was measured at $517 \mathrm{~nm}$ using a spectrophotometer (Synergy LX, BioTek, Instruments, Inc., USA). Ascorbic acid (10-50 $\mu \mathrm{g} / \mathrm{mL})$ was used as positive control and 50\% dimethylsulphoxide (DMSO) only as a negative control. All the experiments of different concentrations of ascorbic acid/plant extract were carried out in triplicate. The inhibitory concentration $\left(\mathrm{IC}_{50}\right)$ value was then calculated by the software.

\section{Statistical analysis}

Gen 5 Microplate Data Collection and Analysis Software and Microsoft Excel were used for data analysis. The $\mathrm{IC}_{50}$ value was calculated using Graph Pad Prism version 8 software and the results were expressed as mean value \pm standard error of the mean (SEM).

\section{Antibacterial activity}

In vitro assessment of antibacterial activity of the methanolic and ethanolic extracts of young and mature leaves of C. tamala was performed using the agar well diffusion method as per guidelines of the Clinical and Laboratory Standards Institute (CLSI) [24]. Briefly, six wells (20 mm apart from one another) were bored in the bacteria cultured plates. The wells were loaded with 20 $\mu \mathrm{L}$ of the respective extracts $(50 \mathrm{mg} / \mathrm{mL})$ dissolved in DMSO. Neomycin is already marketed antibiotic used as positive control while $50 \%$ DMSO was used as a negative control. Petri plates were then incubated at $37^{\circ} \mathrm{C}$ for 24 hours and measured zone of inhibition (ZOI).

\section{Results and Discussion}

\section{Antioxidant activity}

Inhibitory concentration $\left(\mathrm{IC}_{50}\right)$ of standard ascorbic acid (10-50 $\left.\mu \mathrm{g} / \mathrm{mL}\right)$ and different extracts of C. tamala (31.25-500 $\mu \mathrm{g} /$ $\mathrm{mL}$ ) were calculated and presented in Table 1. 
Table 1: $C_{50}$ values of antioxidant activity

\begin{tabular}{|l|l|}
\hline Sample & $\mathbf{I C}_{\mathbf{5 0}}(\boldsymbol{\mu} \mathbf{g} / \mathbf{m L})$ \\
\hline Ascorbic acid & $33.53 \pm 0.97$ \\
\hline MEY & $67.19 \pm 14.96$ \\
\hline MEM & $75.70 \pm 18.52$ \\
\hline EEM & $186.78 \pm 16.87$ \\
\hline EEY & $388.19 \pm 94.47$ \\
\hline
\end{tabular}

MEY: Methanolic extract of young leaves, MEM: Methanolic extract of mature leaves, EEM: Ethanolic extract of mature leaves, EEY: Ethanolic extract of young leaves.

\section{Antibacterial activity}

The diameter of inhibition zone values of all extracts of leaves and young leaves of C. tamala was presented in Table 2.

Table 2: Showing the diameter of zone of inhibition $(\mathrm{mm})(\Phi)$

\begin{tabular}{|c|c|c|c|c|}
\hline Sample & Staphylococcus aureus & Escherichia coli & $\begin{array}{c}\text { Salmonella } \\
\text { typhimurium }\end{array}$ & $\begin{array}{c}\text { Klebsiella } \\
\text { pneumoniae }\end{array}$ \\
\hline MEM & - & 12 & 12 & - \\
\hline MEY & 9 & 18 & 15 & - \\
\hline EEM & - & 18 & 14 & - \\
\hline EEY & 24 & 19 & 13 & 14 \\
\hline
\end{tabular}

-: No zone of inhibition, Concentration: $50 \mu \mathrm{g} / \mathrm{mL}$ in each well, $\Phi$ : Diameter of the well (6mm), ${ }^{*}:$ positive control, Staphylococcus aureus: ATCC 25923, Escherichia coli: ATCC 25922, Salmonella typhimurium: ATCC 14028, Klebsiella pneumoniae: ATCC 700603
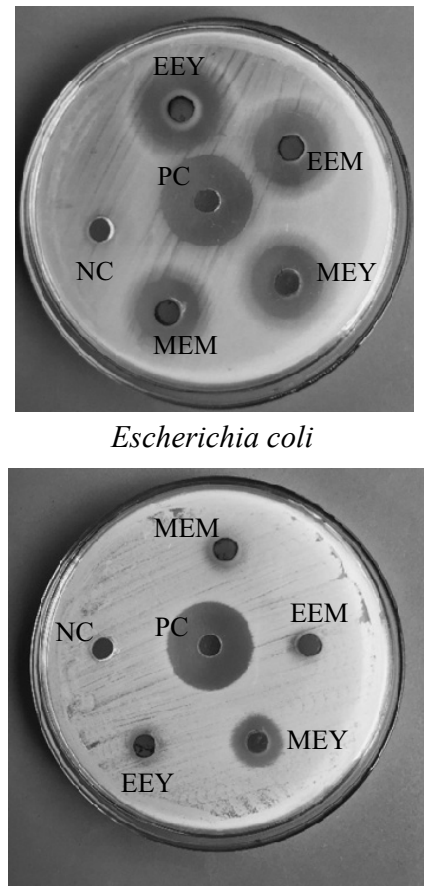

Staphylococcus aureus

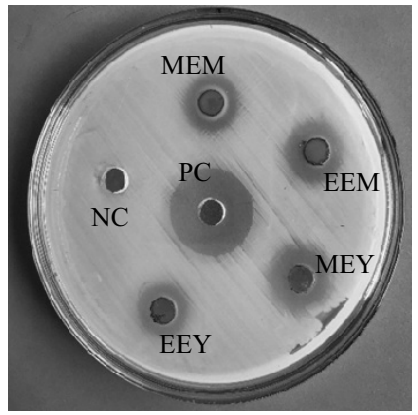

Salmonella typhimurium

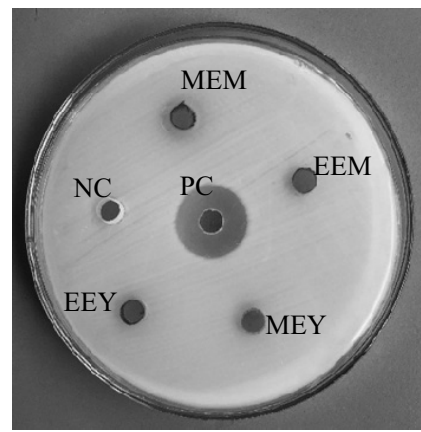

Klebsiella pneumoniae

Fig. 1. Antibacterial activity of different extracts of Cinnamomum tamala on selected bacteria; 
positive control (PC), negative control (NC), MEY (Methanolic Extract of Young leaves), MEM (Methanolic Extract of Mature Leaves), EEY (Ethanolic Extract of Young leaves), EEM (Ethanolic Extract of Mature Leaves)

The result of antibacterial activity showed that all the extracts could inhibit Escherichia coli and Salmonella typhimurium. At the same time, Staphylococcus aureus showed the zone of inhibition only in MEY and no inhibition in Klebsiella pneumoniae by any of the extracts, as shown in table 2 and figure 1.

\section{Antioxidant activity}

The antioxidants/sample react with the stable free radical, i.e. 1, 1-diphenyl-2-picrylhydrazyl (deep violet colour) and transform it to 1, 1-diphenyl-2-picrylhydrazine with discolouration. The degree of discolouration indicates the free radical scavenging potentials of the sample/antioxidant, and it has been found that known antioxidant such as cysteine, glutathione, ascorbic acid, tocopherol, polyhydroxy aromatic compounds (hydroquinone, pyrogallol, etc.) reduce and decolourize 1,1-diphenyl-2picrylhydrazyl by their hydrogen donating ability [25]. Among the four extracts, methanolic extracts of young leaves showed higher antioxidant activity having $\mathrm{IC}_{50} 67.19 \pm 14.96 \mu \mathrm{g} / \mathrm{mL}$. Ethanolic extract of young leaves showed the lowest antioxidant potency with $\mathrm{IC}_{50} 388.19 \pm 94.47 \mu \mathrm{g} / \mathrm{mL}$. The differences in antioxidant activity of different extracts from plants may be due to different phytochemicals in different extracts. Phenolics and flavonoids are the primary compounds responsible for exhibiting antioxidant activity [26].

It was previously reported that the $\mathrm{IC}_{50}$ value of standard ascorbic acid was $3.21 \mu \mathrm{g} / \mathrm{mL}$, where the methanolic extract of $C$. tamala give the $\mathrm{IC}_{50}$ value of $6.0 \mu \mathrm{g} / \mathrm{mL}$ at the concentration range of $100-5 \mu \mathrm{g} / \mathrm{mL}$ [27]. The $\mathrm{IC}_{50}$ value of ethanolic extract of C. tamala leaves was $13.55 \mu \mathrm{g} / \mathrm{mL}$, and that of standard ascorbic acid was $5.35 \mu \mathrm{g} / \mathrm{mL}$ at the concentration range of $500-1 \mu \mathrm{g} / \mathrm{mL}$ [28]. It was also revealed that the $\mathrm{IC}_{50}$ value of standard ascorbic acid was $22.78 \mathrm{mg} / \mathrm{mL}$ and that of methanolic extract of leaves of C. tamala was $157.58 \mathrm{mg} / \mathrm{mL}$ at the concentration range of $500-0.98 \mu \mathrm{g} / \mathrm{mL}$ [14].

Phenolic and flavonoids are responsible for reducing DPPH radical by their hydrogen donating ability, as reported [29], [30]. It was demonstrated that Kaempferol-7-O-rhamnoside was a well-known flavonoid glycoside, which has been reported to possess an excellent inhibitory effect on lipid peroxidation, DPPH free radical and superoxide radical in $70 \%$ ethanolic extracts of Cinnamomum osmopholeum twigs [31]. It was reported that Cinnamomum osmopholeum twigs extract in $70 \%$ acetone showed excellent antioxidant activities, and the active compounds are proanthocyanidin and condensed tannin [32]. The aqueous extract of leaves of $C$. tamala contains phenol $(20.83 \pm 0.11)$, ascorbate $(22.30 \pm 0.21)$ and carotenoids $(0.82 \pm 0.04) \mathrm{mg} / \mathrm{g}$ dry wt., revealed that $C$. tamala had high antioxidants [33]. The findings mentioned above revealed variations in components of leaves and twigs extracts obtained using different solvents.

Polar sub-fraction was the most vital radical reducer compared with the non-polar one [14], [34]. In the pilot study, young and mature leaf extracts of $C$. tamala were prepared using solvents of different polarities as they differ in their phytochemical constitution. Although methanol and ethanol are both polar solvents, it might be assumed that cold maceration with ethanol did not successfully extract active constituents. Thus, the methanolic extract has less $\mathrm{IC}_{50}$ value as compared to less polar ethanolic extract. Besides these, the variation in antioxidant activity between young and mature leaves might be considered the different antioxidant constituents in them [13].

\section{Antibacterial activity}

In the pilot study, antibacterial activity against gram-negative strains (Escherichia coli and Salmonella typhimurium) are shown to be effective in both methanol and ethanol extracts of young and mature leaves as compared to gram-positive bacteria Staphylococcus aureus, as shown in table 2 and figure 1. Among four extracts, a better antibacterial activity was recorded in ethanolic extract of young leaves against Escherichia coli and methanolic extract of young leaves against Salmonella typhimurium, while only methanolic extract of young leaves showed inhibition against Staphylococcus aureus. However, there was no inhibition against Klebsiella pneumoniae by any extracts at the concentration of $50 \mu \mathrm{g} / \mathrm{mL}$.

Previous studies reported that the different solvent extracts including n-hexane, dichloromethane, water, and isobutanol extract of leaves of $C$. tamala exhibited an extra degree of inhibition against selected gram-positive and gram-negative bacteria [35]. Many authors reported that the antimicrobial constituents of Cinnamomum extracts are cinnamaldehyde and eugenol [36], [37]. Cinnamaldehyde was identified in Cinnamomum zeylanicum that inhibits amino acid decarboxylase activity and has been 
active against many pathogenic bacteria [38], [39]. Cinnamaldehyde interferes with biological processes involving electron transfer and reacts with nitrogen-containing components including, proteins and nucleic acids [40]. Gram-negative bacteria were slightly less susceptible to the action of cinnamaldehyde since they possess an outer membrane surrounding the cell wall, which restricts the diffusion of hydrophobic compounds through its lipopolysaccharide covering [41], [42].

However, the results from this current study revealed that gram-negative bacteria were more susceptible because extracts of C. tamala might contain certain constituents, which enable the extract to overcome the barrier in gram-negative bacteria. Besides these, the variation of antibacterial activity between young and mature leaves might be considered to be the presence of different antibacterial constituents in them. Therefore, the bioactive components with antimicrobial properties should be analyzed for further study.

\section{Conclusions}

In this study, the different solvent extracts of $C$. tamala were screened for antioxidant and antibacterial activity. The antioxidant activity revealed that methanol extract inhibits more effectively as compared to ethanol extracts. Besides these, methanol and ethanol extract had a wide range of antibacterial activities against Escherichia coli and Salmonella typhimurium among four tested bacteria. This study further helps to pave the pathway to the scientific community regarding the pharmacological potentials of C. tamala and provides the rationale for further identification, isolation and characterization of its bioactive principles.

\section{Acknowledgements}

The authors extend their appreciation to the Central Department of Chemistry, Tribhuvan University, for providing laboratory facilities. Special thanks go to Prof. Dr Suresh Kumar Ghimire of Central Department of Botany, Tribhuvan University for plant identification, and Department of Biotechnology, National College, Kathmandu, for the antibacterial test.

\section{References}

1. J. D. Stainton. Forests of Nepal, $1^{\text {st }}$ edition, John Murray, London, 1972, 7-9.

2. J. Gertsch. How Scientific is the Science in Ethnopharmacology? Historical Perspectives and Epistemological Problems, Journal of Ethnopharmacology, 2009, 122(2), 177-183.

3. K.C. Nicolaou, J.S. Chen, S.M. Dalby. From Nature to the Laboratory and into the Clinic, Bioorganic and Medicinal Chemistry, 2009, 17(6), 2290-2303.

4. N.P. Manandhar. Ethnobotanical Note on Folklore Remedies of Baglung District Nepal, Contributions to Nepalese Studies, 1993, 20(2), 183-196.

5. A. Rijal. Living Knowledge of the Healing Plants: Ethno-phytotherapy in the Chepang Communities from the Mid-Hills of Nepal, Journal of Ethnobiology and Ethnomedicine, 2008, 4(1), 23.

6. M.B. Rokaya, Z. Münzbergová, B. Timsina. Ethnobotanical Study of Medicinal Plants from the Humla District of Western Nepal, Journal of Ethnopharmacology, 2010, 130(3), 485-504.

7. B. Malla, D.P. Gauchan, R.B. Chhetri. An Ethnobotanical Study of Medicinal Plants Used by Ethnic People in Parbat District of Western Nepal, Journal of Ethnopharmacology, 2015, 165, 103-117.

8. O. Polunin, A. Stainton, A. Farrer. Concise Flowers of the Himalayas, Oxford University Press, 1987, 123-124.

9. D. Lamichhane, N.K. Karna. Harvesting Methods of C. tamala Leaves in Private Land: A Case Study from Udayapur District, Nepal, Banko Janakari, 2009, 19(2), 20-24.

10. R.D. Gaur. Traditional Dye Yielding Plants of Uttarakhand, India, Indian Journal of Natural Products and Resources, 2008, 7(2), 154-165.

11. I.P.S. Kapoor, B. Singh, G. Singh. Essential Oil and Oleoresins of C. tamala (tejpat) as Natural Food Preservatives for Pineapple Fruit Juice, Journal of Food Processing and Preservation, 2008, 32(5), 719-728. 
12. S. Mehta, V.K. Purohit, H.C. Andola. Pharmacological Activities of C. tamala Nees and Eberm and Medical Implication: A Review, Medicinal and Aromatic Plants, 2014, 3(174), 2167-0412.

13. K.N. Prasad, B. Yang, X. Dong, G. Jiang, H. Zhang, H. Xie, Y. Jiang. Flavonoid Contents and Antioxidant Activities from Cinnamomum species, Innovative Food Science and Emerging Technologies, 2009, 10(4), 627-632.

14. S. Sultana, F.A. Ripa, K. Hamid. Comparative Antioxidant Activity Study of Some Commonly Used Spices in Bangladesh, Pakistan Journal of Biological Sciences, 2010, 13(7), 340.

15. P. Jeyasree, P. Dasarathan. Screening of Phytochemicals and Immunomodulatory Potential of a Medicinal Plant, $C$. tamala, International Journal of Pharmaceutical Sciences Research, 2012, 3, 1049-1052.

16. J. Parekh. In vitro Screening of Antibacterial Activity of Aqueous and Alcoholic Extracts of Various Indian Plant Species against Selected Pathogens from Enterobacteriaceae, African Journal of Microbiology Research, 2007, 1(6), 92-99.

17. R.S. Thombre, V. Shinde, E. Thaiparambil, S. Zende, S. Mehta. Antimicrobial Activity and Mechanism of Inhibition of Silver Nanoparticles against Extreme Halophilic Archaea, Frontiers in Microbiology, 2016, 7, 1424.

18. P. Sun, T. Wang, L. Chen, B. Yu, Q. Jia, K. Chen, H. Fan, Y. Li, H. Wang. Trimer Procyanidin Oligomers Contribute to the Protective Effects of Cinnamon Extracts on Pancreatic $\beta$-cells in vitro, Acta Pharmacologica Sinica, 2016, 37(8), $1083-1090$.

19. K.N. Udupa, S.N. Tripathi, H.M. Chandola. Effect of C. tamala on Plasma Insulin vis-à-vis Blood Sugar in Patients of Diabetes Mellitus, Journal of Research in Ayurveda. Siddha, 1980, 1, 345-357.

20. T. Wang, P. Sun, L. Chen, Q. Huang, K. Chen, Q. Jia, Y. Li, H. Wang. Cinnamtannin D-1 Protects Pancreatic $\beta$-Cells from Palmitic acid-induced Apoptosis by Attenuating Oxidative Stress, Journal of Agricultural and Food Chemistry, 2014, 62(22), 5038-5045.

21. D. Shahwar, S. Ullaha, M.A. Khan, N. Ahmad, A. Saeed, S. Ullah. Anticancer Activity of Cinnamon tamala Leaf Constituents towards Human Ovarian Cancer Cells, Pakistan Journal of Pharmaceutical Sciences, 2015, 28(3), 969-972.

22. R.K. Dumbre, M.B. Kamble, V.R. Patil. Inhibitory Effects by Ayurvedic Plants on Prostate Enlargement Induced in Rats, Pharmacognosy Research, 2014, 6(2), 127.

23. K. Khadayat, B.P. Marasini, H. Gautam, S. Ghaju, N. Parajuli. Evaluation of the Alpha-amylase Inhibitory Activity of Nepalese Medicinal Plants Used in the Treatment of Diabetes Mellitus, Clinical Phytoscience, 2020, 6(1), 34.

24. J.B. Patel. Performance Standards for Antimicrobial Susceptibility Testing, Clinical and Laboratory Standards Institute, 2017, 200-202.

25. M.S. Blois. Antioxidant Determinations by the Use of a Stable Free Radical, Nature, 1958, 181(4617), 1199-1200.

26. I. Pathak, M. Niraula. Assessment of Total Phenolic, Flavonoid Content and Antioxidant Activity of Ocimum sanctum Linn, Journal of Nepal Chemical Society, 2019, 40, 30-35.

27. R. Al-Mamun, A. Hamid, M.K. Islam, J.A. Chowdhury, A.Z. Azam. Lipid Lowering Activity and Free Radical Scavenging Effect of C. tamala (family: Lauraceae), International Journal of Natural Sciences, 2011, 1(4), 93-96.

28. S. Akter, M.A. Ali, R.K. Barman, B.M. Rahman, M. Imam, I. Wahed. In vitro Antioxidant and Cytotoxic Activity of Ethanolic Extract of C. tamala (Tejpat) Leaves, International Journal of Pharmaceutical Sciences Research, 2015, 6(3), $531-536$.

29. K.N. Prasad, S. Divakar, G.R. Shivamurthy, S.M. Aradhya. Isolation of a Free Radical-scavenging Antioxidant from Water Spinach (Ipomoea aquatica Forsk), Journal of the Science of Food and Agriculture, 2005, 85(9), 1461-1468.

30. M. Zhao, B. Yang, J. Wang, B. Li, Y. Jiang. Identification of the Major Flavonoids from Pericarp Tissues of Lychee Fruit in Relation to their Antioxidant Activities, Food Chemistry, 2006, 98(3), 539-544. 
31. M.T. Chua, Y.T. Tung, S.T. Chang. Antioxidant Activities of Ethanolic Extracts from the Twigs of Cinnamomum osmophloeum, Bioresource Technology, 2008, 99(6): 1918 - 1925.

32. G.M. Lin, Y.H. Chen, P.L. Yen, S.T. Chang. Antihyperglycemic and Antioxidant Activities of Twig Extract from Cinnamomum osmophloeum, Journal of Traditional and Complementary Medicine, 2016, 6(3): 281-288.

33. U. Chakraborty, H. Das. Antidiabetic and Antioxidant Activities of C. tamala Leaf Extracts in Stz-treated Diabetic Rats, Global Journal of Biotechnology and Biochemistry, 2010, 5(1), 12-18.

34. C. Sarikurkcu, B. Tepe, D. Daferera, M. Polissiou, M. Harmandar. Studies on the Antioxidant Activity of the Essential oil and Methanol Extract of Marrubium globosum subsp. Globosum (Lamiaceae) by Three Different Chemical Assays, Bioresource Technology, 2008, 99(10), 4239-4246.

35. N. Sanjay, M.M. Tiwari, A. Chauhan. Elementals Profile of Traditional Some Important Medicinal Plants of Uttarakhand State, India, Reproduction and Opinion, 2010, 2(6), 34-36.

36. A.R. Shahverdi, H.R. Monsef-Esfahani, F. Tavasoli, A. Zaheri, R. Mirjani. Trans-cinnamaldehyde from Cinnamomum zeylanicum Bark Essential Oil Reduces the Clindamycin Resistance of Clostridium difficile in vitro, Journal of Food Science, 2007, 72(1), S055-S058.

37. S.Y. Wu, Y.T. Kao, S.T. Chang. Antifungal Activities of Extracts and Essential oil's Constituents from Cinnamomum kanehirae, Forest Products Industries, 2003, 22(3), 197-204.

38. C.N. Wendakoon, M. Sakaguchi. Inhibition of Amino Acid Decarboxylase Activity of Enterobacter aerogenes by Active Components in Spices, Journal of Food Protection, 1995, 58(3), 280-283.

39. P. Suresh, V.K. Ingle, V. Vijayalakshmi. Antibacterial Activity of Eugenol in Comparison with other Antibiotics, Journal of Food Science and Technology (Mysore), 1992, 29(4), 254-256.

40. C. Gupta, A.P. Garg, R.C. Uniyal, A. Kumari. Comparative Analysis of the Antimicrobial Activity of Cinnamon oil and Cinnamon extract on Some Food-borne Microbes, African Journal of Microbiology Research, 2008, 2(9), $247-251$.

41. C. Ratledge, S.G. Wilkinson. An Overview of Microbial Lipids, Microbial Lipids, 1988, 1, 3-22.

42. M. Vaara. Agents that Increase the Permeability of the Outer Membrane, Microbiology and Molecular Biology Reviews, 1992, 56(3), 395-411. 